\title{
APLIKASI SEWA PERALATAN KONSTRUKSI PADA CV TRITAMA ULLY ABADI BERBASIS DESKTOP
}

\author{
Mitra Kaswadi \\ Program Studi Teknik Informatika, Fakultas Teknik dan Ilmu Komputer, \\ Universitas Indraprasta PGRI \\ Jalan Raya Tengah No 80, Kelurahan Gedong, Pasar Rebo, Jakarta Timur \\ mitradsnakerz24@gmail.com
}

\begin{abstract}
Abstrak
Penelitian ini dilakukan dengan menggunakan metode grounded research yaitu sebuah metode yang dilakukan berdasarkan fakta yang sebenarnya dan menggunakan analisa perbandingan dengan tujuan mengadakan generalisasi empiris, menetapkan konsep, membuktikan teori, mengembangkan teori, pengumpulan data dan analisa data dalam waktu yang bersamaan Tujuan dari penelitian adalah untuk memudahkan pekerjaan staf dan admin dalam mengelola data peralatan konstruksi sehingga dapat terselesaikan secara lebih cepat, tepat dan efisien. Metode penelitian yang digunakan dalam rancangan aplikasi sewa peralatan konstruksi pada cv. tritama ully abadi ini adalah studi lapangan yaitu pengamatan langsung, wawancara dengan pihak terkait dengan melakukan dokumentasi untuk mendapatkan informasi yang dibutuhkan. Selain itu, peneliti juga melakukan penelitian dengan metode kepustakaan berdasarkan referensi dari berbagai media yang memuat informasi yang dibutuhkan, menganalisa kebutuhan, perancangan, implementasi, pengkodean, dan pengujian. Pada penelitian ini telah dirancang sebuah Aplikasi Sewa Peralatan Konstruksi dimana dalam membangun sistem ini digunakan alat bantu perancangan sistem yaitu Diagram Aliran Data (DAD) Konteks, Nol dan Rinci serta dengan menggunakan bahasa pemrograman JAVA dengan Netbeans IDE, dan database MYSQL menggunakan XAMPP.
\end{abstract}

Kata Kunci: Aplikasi, Sewa Peralatan, Java netbeans.

\begin{abstract}
This research was conducted using the grounded research method, which is a method based on actual facts and using comparative analysis with the aim of making empirical generalizations, establishing concepts, proving theories, developing theories, collecting data and analyzing data at the same time. facilitate the work of staff and admin in managing construction equipment data so that it can be completed more quickly, precisely and efficiently. The research method used in the design of the construction equipment rental application at CV. Tritama Ully Abadi is a field study, namely direct observation, interviews with related parties by documenting to obtain the required information. Besides, Researchers also conducted research with the library method based on references from various media containing the information needed, analyzing needs, designing, implementing, coding, and testing. In this study, a Construction Equipment Rental Application has been designed where in building this system a system design tool is used, namely Context, Zero and Detailed Data Flow Diagrams (DAD) and using the JAVA programming language with the Netbeans IDE, and the MYSQL database using XAMPP.
\end{abstract}

Keyword: Application, Equipment Rental, Java Netbeans.

\section{PENDAHULUAN}

Berkembangnya teknologi informasi mengubah manusia dalam menyelesaikan semua pekerjaannya. Dahulu manusia menyimpan semua informasi dan dokumen menggunakan buku yang disimpan dalam lemari dokumen, maka sekarang berubah menggunakan komputer untuk menyimpan data-data suatu perusahaan (Teguh, 2014). CV. Tritama Ully Abadi memiliki kurang lebih 10 alat konstruksi yang terdiri dari excavator, dump truck, concrete vibrator, dan lain-lain. Alat-alat tersebut dikelola oleh staf dan administrasi secara manual, yaitu dengan menggunakan buku catatan yang sifatnya sementara. Oleh karena itu, agar dapat menunjang efektivitas dan efisiensi serta mempermudah pengolahan data alat konstruksi, maka dibuatlah aplikasi sewa peralatan konstruksi berbasis java pada CV. Tritama Ully Abadi. 
Berkaitan dengan permasalahan sebelumnya, rumusan masalah yang diambil dari penelitian ini yaitu bagaimana rancangan pengolahan data peminjam dan pengembalian pada alat konstruksi CV. Tritama Ully Abadi dengan menggunakan sistem komputerisasi, bagaimana hasil rancangan sistem komputerisasi pengolahan data CV. Tritama Ully Abadi. Berdasarkan rumusan masalah, maka tujuannya penelitian ini adalah membuat model rancangan sistem peng-input-an data, menunjukkan hasil sistem komputerisasi dalam peng-input-an data alat konstruksi. Manfaat Penelitian dari penelitian ini yaitu untuk Mengetahui kondisi dan masalah sebenarnya yang terjadi di dunia kerja yaitu dapat melakukan pengembangan media aplikasi sistem informasi.

\section{PENELITIAN RELEVAN}

Dalam rangka mendapat hasil penelitian yang baik, selain melakukan penelitian langsung peneliti juga melakukan kajian perpustakaan dari hasil penelitian yang telah dilakukan. Berikut ini hasil penelitian yang menjadi acuan:" Perancangan Aplikasi Penyewaan Alat Berat berbasis Web pada PT. Indotruck Citra Permata dibuat Oleh Lola Yorita Astri, Jurnal Processor, Volume, 12 No, 2, Tahun 2017. Tujuan penelitian isi pengolahan data yang terkomputerisasi merupakan media yang tepat untuk mecapai hasil yang maksimal, karena mempunyai kemampuan yang tinggi dalam ketelitian pengolahan data (Astri, 2017). Kesimpulan yang diperoleh adalah Perubahan sistem manual menjadi suatu sistem yang terkomputerisasi dilakukan agar tingkat kesalahan dalam melakukan pengolahan data penyewaan alat dapat diminimalisir dan dapat memberikan pelayanan yang baik serta hasil keluaran atau laporan yang dibutuhkan sesuai dengan yang diharapkan. "Aplikasi Penyewaan Alat Berat pada PT. Tri Harfi Mandiri menggunakan Pemograman Visual dibuat Oleh Fakhriani Ekawati, Jurnal Technologia, Volume 9, No 4, Tahun 2018, Tujuan penelitian ini adalah untuk mengetahui sistem yang berjalan, merancang serta mengimplementasikan sistem informasi. Kesimpulan yang diperoleh adalah Pengenalan teknologi yang tidak secara langsung dalam meningkatkan efisiensi pengolahan data pelanggan dalam melakukan penyewaan alat konstruksi (Ekawati, 2018).

\section{METODE PENELITIAN}

Metode penelitian yang digunakan oleh peneliti adalah metode grounded (grounded research) yaitu suatu metode penelitian berdasarkan pada fakta dan menggunakan analisis perbandingan dengan tujuan mengadakan generalisasi empiris, menetapkan konsep, membuktikan teori, mengembangkan teori, pengumpulan dan analisis data dalam waktu yang bersamaan (Barnabas, n.d.). Metode pengumpulan data yang digunakan peneliti untuk mendapatkan data dan informasi yang mendukung hasil dari penelitian ini antara lain: Studi Kepustakaan dan Studi Lapangan. Studi kepustakaan digunakan untuk pengumpulan data dan informasi dari kutipan-kutipan buku, peraturan perundang-undangan, artikel-artikel, hasil laporan, serta bahan lainnya yang berkaitan dengan penelitian ini (Kristanto, 2012). Dari bahan-bahan tersebut diambil teori-teori yang dijadikan landasan untuk menganalisa masalah yang ditemukan dalam penelitian dan digunakan untuk menyelesaikan masalah tersebut. Studi lapangan dilakukan secara langsung untuk mengumpulan data yang berhubungan dengan sistem penelusuran dari alat konstruksi CV. Tritama Ully Abadi.

Dalam studi lapangan ini di pergunakan untuk teknik pengumpulan data antara lain dengan cara: Observasi dan Wawancara. Observasi adalah suatu cara pengumpulan data dengan mengadakan pengamatan langsung terhadap suatu objek dalam suatu periode tertentu yang diamati.(Sugiyono, 2013) Tujuan observasi yaitu untuk mengetahui secara langsung data statistik sistem penyewaan alat konstruksi yang digunakan di CV. Tritama Ully Abadi. Hasil observasi digunakan peneliti untuk mendapatkan data yang akurat dan relevan sesuai dengan tujuan penelitian. Wawancara adalah salah satu teknik pengumpulan data yang dilakukan dengan cara tanya jawab antara interviewer (penanya) dengan responden (penjawab). Dalam wawancara pada bulan April peneliti sebagai penanya dibantu oleh Bapak Binsar Rajagukguk sebagai penjawab selaku staff kepegawaian. Dalam wawancara ini peneliti bertanya mengenai program yang sudah ada, sejarah, dan data-data lain untuk melengkapi penelitian dan pembuatan program. 


\section{HASIL DAN PEMBAHASAN}

Aturan sistem aplikasi sewa alat konstruksi pada CV. Tritama Ully Abadi yang berjalan antara lain:

1. Bila ada alat konstruksi yang masuk, maka admin membuat nota, kemudian di proses untuk penyewaan alat konstruksi.

2. Pengolahan data alat konstruksi masuk sebagai informasi admin.

3. Hasil data yang diolah, disimpan di rak penyimpanan data.

4. Admin memeriksa pesanan pelanggan untuk melakukan penyewaaan alat konstruksi.

5. Admin menyerahkan pesanan alat konstruksi yang disewa oleh pelanggan untuk melakukan pengeluaran alat konstruksi.

Sistem yang baru diusulkan merupakan komputerisasi dari sistem yang lama, di mana cara kerja sistem yang baru tidak jauh berbeda dengan yang lama(Al-Bahra bin, 2015). Sistem yang baru, yaitu sistem sewa alat konstruksi berbasis java. Dengan peralihan sistem yang lama ke sistem baru, diharapkan dapat mengatasi permasalahan yang ada (Komputer, 2015), meliputi:

1. Ketelitian, yaitu informasi yang dihasilkan lebih lengkap dan jelas.

2. Ketepatan waktu, yaitu informasi yang dibutuhkan dapat diproses dengan cepat dan tepat.

3. Mengefisienkan waktu dalam hal penyewaan dan lain sebagainya untuk memperoleh informasi yang dibutuhkan.

\section{Diagram Konteks}

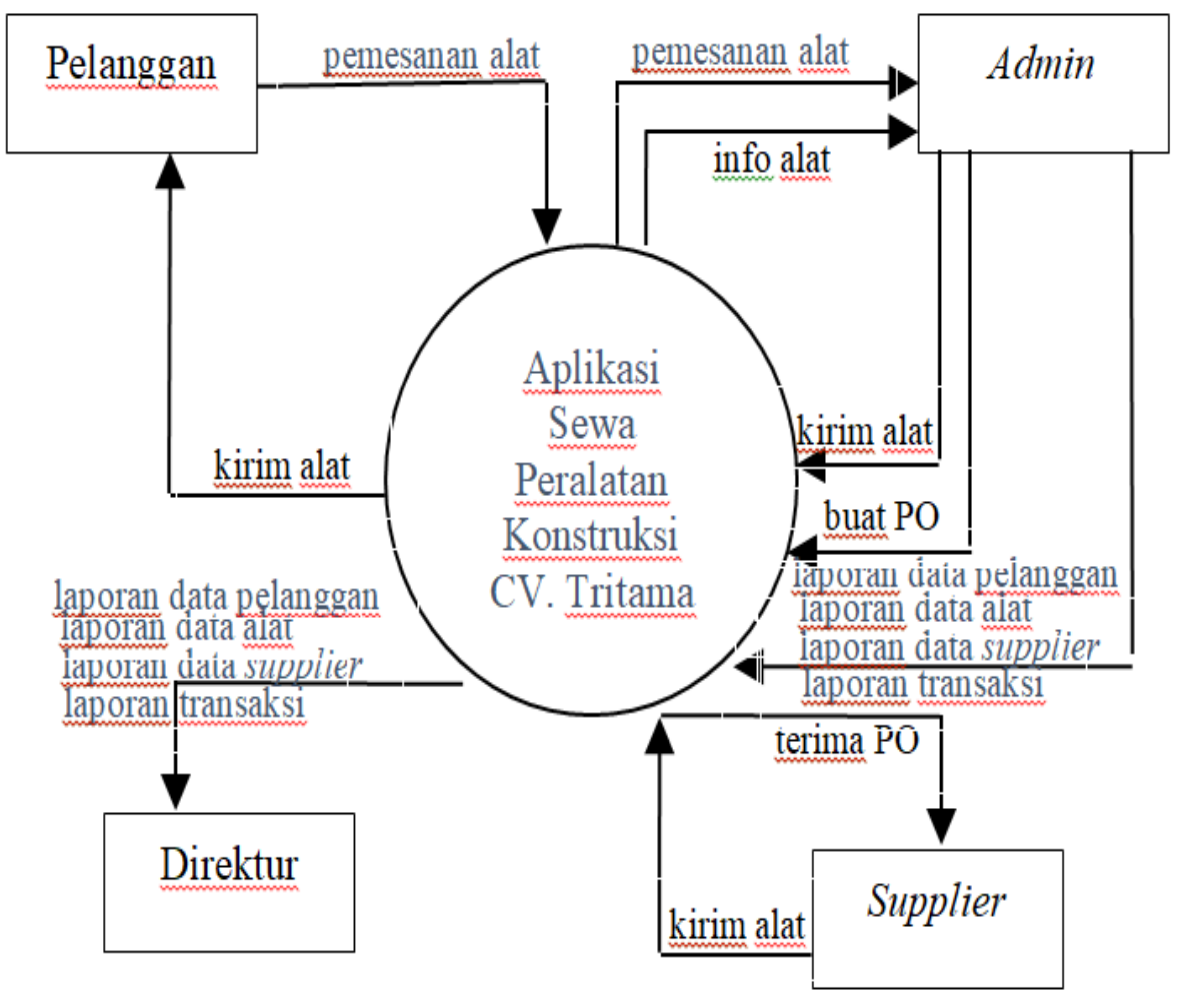

Gambar 1. Diagram konteks 


\section{ERD (Entity Relationship Diagram)}

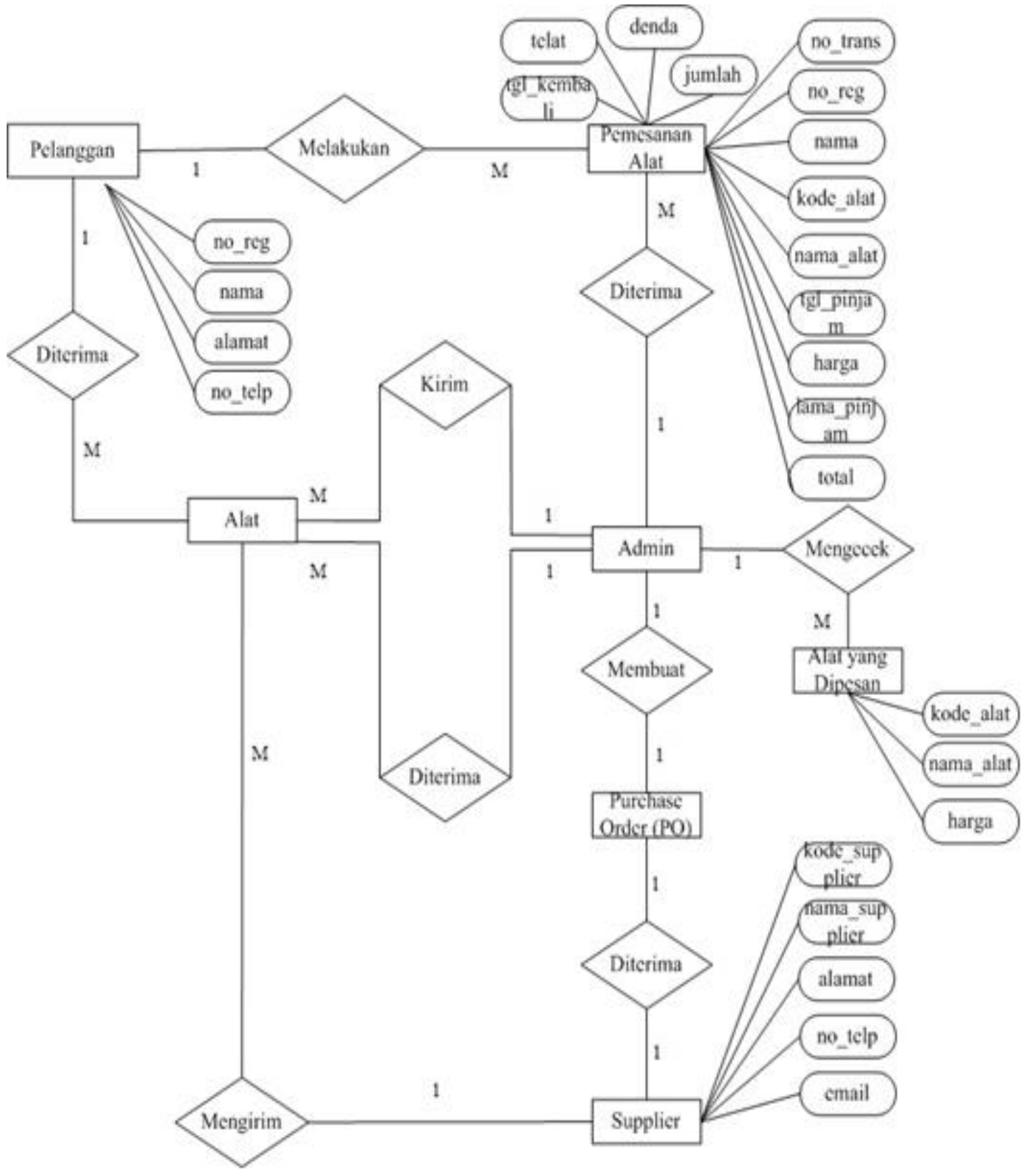

Gambar 2. Entity Relationship Diagram (ERD) 


\section{Tampilan Layar}

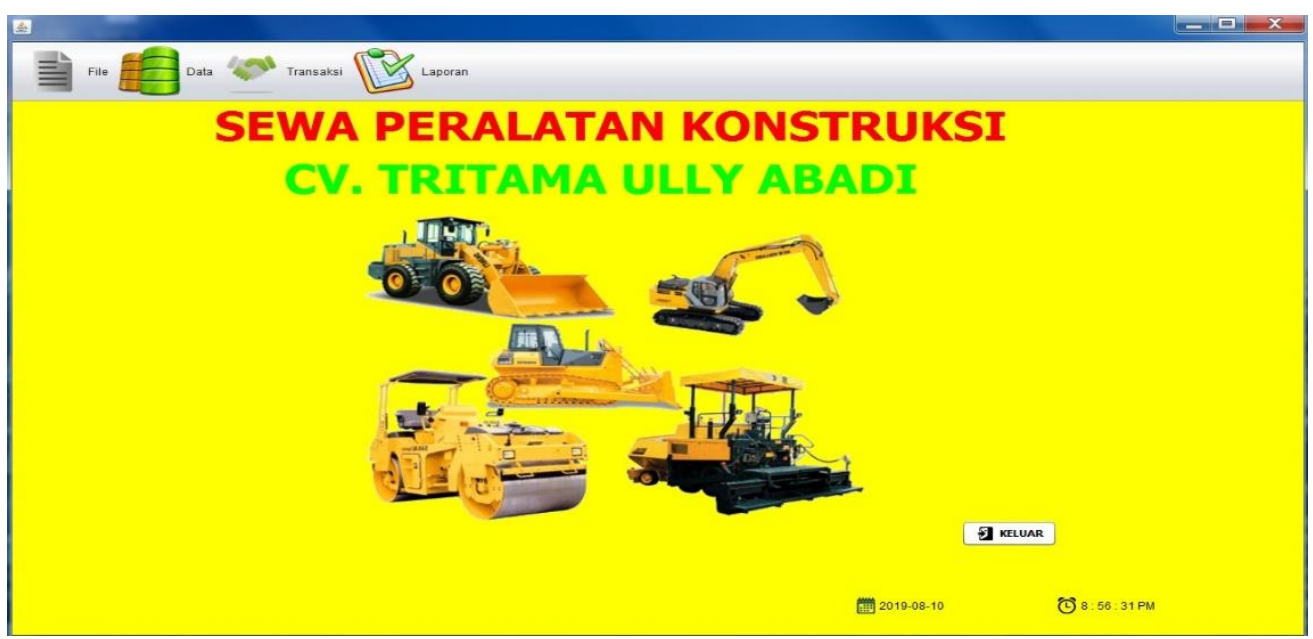

Gambar 3. Tampilan menu utama

Tampilan menu utama ini terdapat beberapa icon menu yang akan menampilkan form-form masukan dan keluaran.

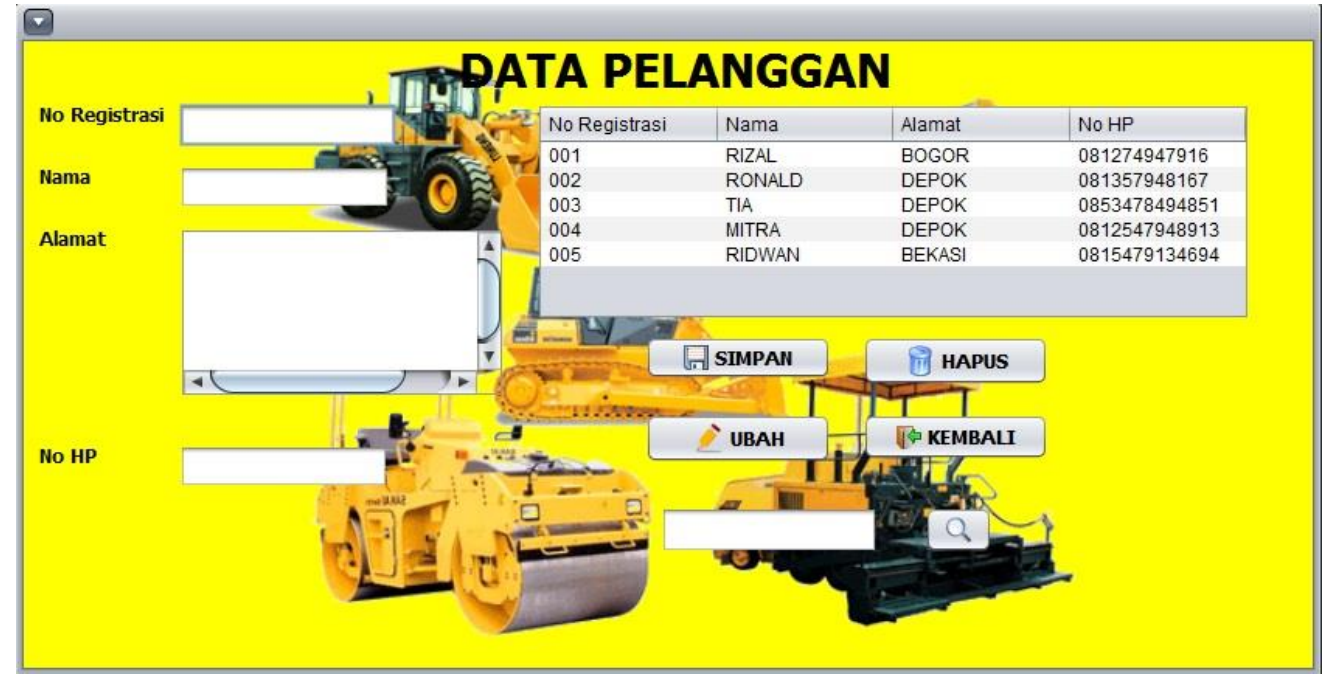

Gambar 4. Tampilan data pelanggan

Pada tampilan form data pelanggan ini, admin dapat melakukan penambahan data pelanggan, mengubah, dan juga menghapus data pelanggan. Untuk menambahkan data pelanggan, admin akan harus mengisi form nomor registrasi, nama, alamat, dan nomor hp. 


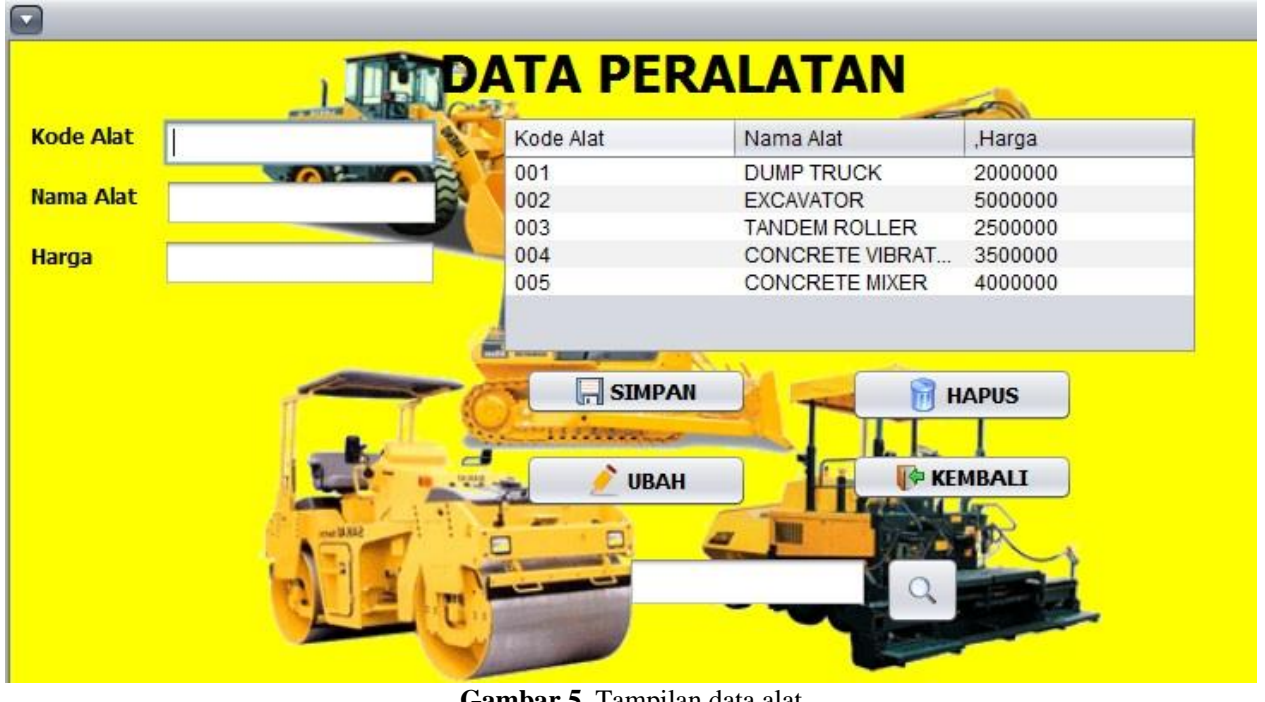

Pada tampilan form data alat ini, admin dapat melakukan penambahan data alat, mengubah, dan juga menghapus data alat. Untuk menambahkan data alat, admin akan harus mengisi form kode alat, nama alat, dan harga. Kemudian memilih button simpan untuk menyimpan.

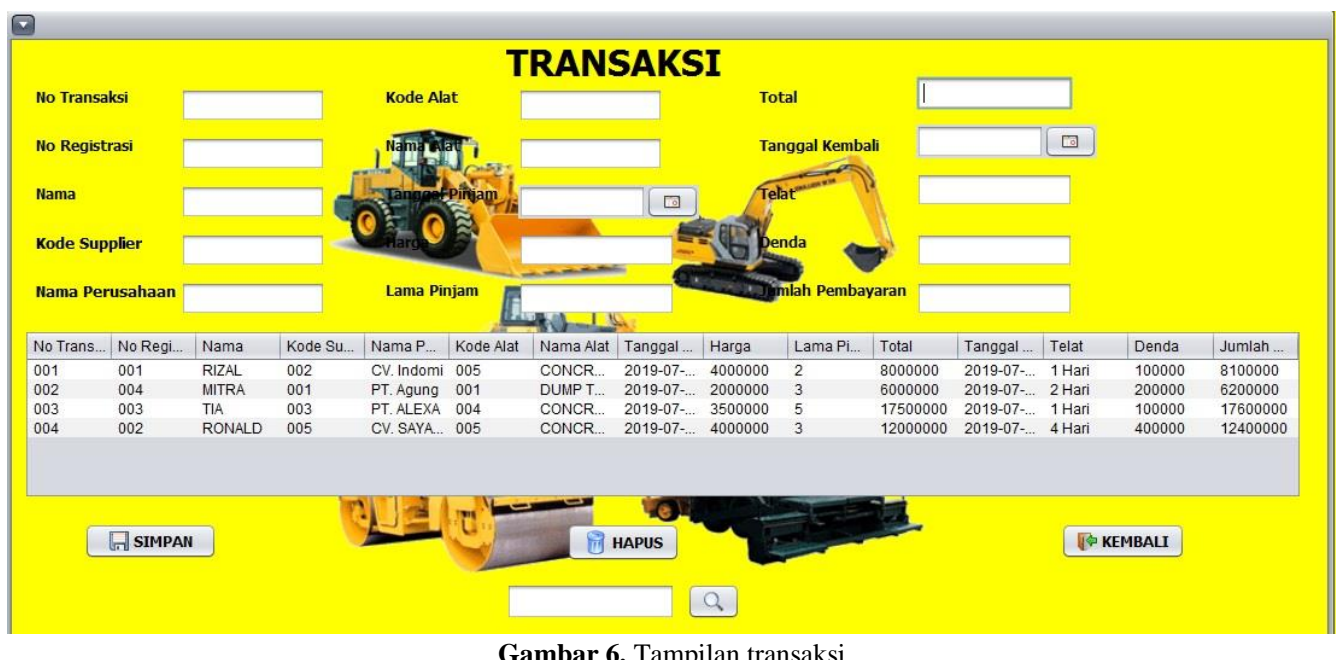

Pada tampilan form transaksi ini, admin dapat melakukan penambahan data transaksi, dan menghapus data transaksi. Untuk menambahkan data transaksi, admin akan harus mengisi form nomor transaksi, nomor registrasi, nama, kode supplier, nama perusahaan, kode alat, nama alat, tanggal pinjam, harga, lama pinjam, total, tanggal kembali, telat, denda, dan jumlah pembayaran. 


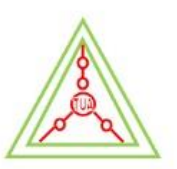

CV. TRITAMA ULLY ABADI

General Contractor \& Sewa Alat Berat

JI Raya Sawangan No 24 Sawangan Kota Depok

Data Peralatan

\begin{tabular}{|c|c|c|}
\hline Kode Alat & Nama Alat & Harga \\
\hline 001 & EXCAVATOR & 4000000 \\
\hline 002 & TANDEM & 3000000 \\
\hline 003 & CONCRETE & 3500000 \\
\hline 004 & CONCRETE & 4000000 \\
\hline 005 & DUMP TRUCK & 2000000 \\
\hline
\end{tabular}

Jakarta, Jumat 16 Agustus 2019

CV. TRITAMA ULLY ABADI

BINSAR

DIREKTUR

Gambar 7. Tampilan Laporan Alat

Pada tampilan laporan data alat ini, admin dapat mencetak data alat dengan cara mengklik button cetak laporan data alat.

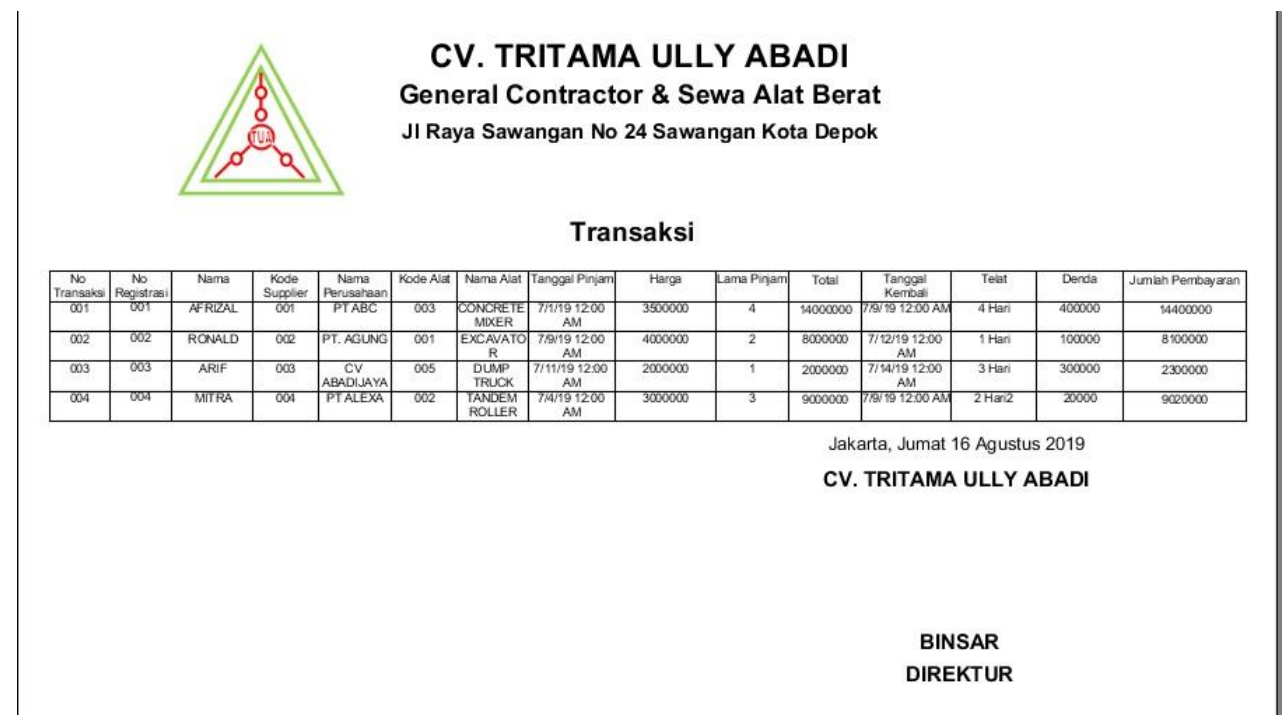

Gambar 8. Tampilan Laporan Transaksi

Pada tampilan laporan transaksi ini, admin dapat mencetak laporan transaksi dengan cara mengklik button cetak pada laporan transaksi.

\section{SIMPULAN}

Setelah aplikasi ini dibuat, pada bagian pendataan dapat memberikan informasi dengan cepat, tepat dan tidak memerlukan banyak waktu dalam memperoleh informasi. Selain itu penyajian informasi tidak dapat dan terdapat kesalahan-kesalahan pada pendataan, tetapi dengan adanya aplikasi ini, penyajian informasi akan tepat dan kesalahan-kesalahan dapat diatasi dengan baik agar tidak terjadi hambatan dalam penyajian informasi. 


\section{DAFTAR PUSTAKA}

Al-Bahra bin, L. (2015). Analisis dan Desain Sistem Informasi (Graha ilmu). Graha ilmu.

Astri Yorita, L. (2017). Perancangan Aplikasi Penyewaan Alat Berat berbasis Web pada PT. Indotruck Citra Permata. Jurnal Processor.

Barnabas, B. (n.d.). Metode Penelitian Grounded Research. Metode Penelitian Grounded Research. https://www.academia.edu/8363807/Grounded_Research_Gr ounded_Theory_Metode_Penelitian_Grounded_oleh_Baren_Barnabas?auto=download

Ekawati, F. (2018). Aplikasi Penyewaan Alat Berat pada PT. TRI HARFI MANDIRI menggunakan Pemograman Visual. Technologia, 9, No 4. https://id.123dok.com/document/zlr24dlz-aplikasi-penyewaan-alat-berat-pada-pt-tri-harfimandiri-menggunakan-pemprograman-visual-fakhriani-ekawati-universitas-islam-kalimantan-muhammad-arsyadal-banjari-banjarmasin-email-fakhrianiekawatigmail-com-abstrak-aplikasi-penyewaan-alat-berat-pada-p.html

Komputer, W. (2015). Membangun Sistem Informasi dengan Java NetBeans dan MySOL No Title (CV Andi Of). CV Andi Offset.

Kristanto. (2012). Perancangan Sistem Informasi dan Aplikasinya (Gava Media). Gava Media.

Suarga. (2010). Dasar Pemograman Komputer Dalam Bahasa Java. Andi Offset.

Sugiyono. (2013). Metode Penelitian Manajemen (Alfabet). Alfabet.

Teguh, W. (2014). Sistem Informasi Konsep Dasar, Analisis, Desain, Dan Implementasi. Graha Ilmu.

W.B, D. (2017). System Analysis and Design Method Edition. McGraw-Hill. 